\title{
The influence of microporosity on porosity-permeability correlation in carbonate rocks
}

Grazielle Oliveira, Marco Ceia, Roseane Missagia, Irineu Lima Neto, Victor Santos, UENF/LENEP.

Copyright 2019, SBGf - Sociedade Brasileira de Geofísica

This paper was prepared for presentation during the $16^{\text {th }}$ International Congress of the Brazilian Geophysical Society held in Rio de Janeiro, Brazil, 19-22 August 2019.

Contents of this paper were reviewed by the Technical Committee of the $16^{\text {th }}$ International Congress of the Brazilian Geophysical Society and do not necessarily represent any position of the SBGf, its officers or members. Electronic reproduction or storage of any part of this paper for commercial purposes without the written consent of the Brazilian Geophysical Society is prohibited.

\section{Abstract}

Carbonate rocks represent more than $50 \%$ of reservoir, and with the development of new technologies and new discoveries, this index tends to increase over the years.

Generally, very heterogeneous carbonate rocks are denominated by micropores in the structure. The microporosity causes difference in the methods of measurement of the petrophysical properties due to different scales that limits some methods of gauging and/or image capture, causing errors of estimates of reserves and petroleum potential. Besides the quantity, the arrangement, the porosity type, and the combination with the macroporosity that makes it difficult to correlate the permeability with the porosity.

In this article, carbonate rocks from Oman of various types of textures, porosity and pores were analyzed and most of them the microporosity is in evidence. Digital image analysis (DIA) was used to identify the macro pore fraction as well as the geometric parameters, while static methods of helium gas porosimetry measured the petrophysical properties of the entire porous system.

\section{Introduction}

The complex process of carbonate rocks formation extends to depositional and diagenetic processes that modify the structure of the pores (Shabaninejad and Haghighi, 2011) causing changes in porosity and permeability. The carbonate sediments generate multimodal pore sizes, implying porous spaces with complex distribution (Clerke, 2007), the minerals that make up these sediments are subject to the effects of diagenesis, such as dissolution, cementation and dolomitization, further increasing the size diversity and pore type (Lucia, 1995).

All these events increasing the complexity of pore structure and diversity of carbonates and result in problems to characterize permeability and porosity (Schon, 2011). Thus, integrated analyses with different methods of estimation and relation with thin section images help in the interpretation of the data.

Petrophysical properties are often measured through gas porosimeter and permeameter. These techniques allow measurements in very small pores in microns scale allowing to understand how the microporosity affects the permeability values. Usually, micropores are related to immobile fluids (Ehrlich et al., 1991) and do not contribute to permeability.

The estimation of the pore geometric parameters through the digital image analysis of thin sections makes it possible to determine the porosity and calculate the permeability. Petrophysical properties estimated from DIA are related to effective porosity - porosity that allows fluid flowage - defined by many authors as the cut off between macroporosity and microporosity (Cantrell and Hagerty. 1999, Erbeli et al., 2004, Bashah and Pierson, 2012). Thereby, the Image porosity is most likely closer related to effective porosity (Movers and Budd, 1996 and Baechle et al., 2004). However, the resolution of the images is a limiting factor of this technique.

The study of petrophysical properties in carbonate rocks has evolved over time. Lucia (1983) determined that the rock fabrics control the petrophysical properties (porosity and permeability). Ehrenberg et al., 2006 studied the porosity- permeability relationship laboratory in carbonate samples of different textures. Knackstedt et al., 2008, modelled the pore system and correlated the petrophysical properties and compared data calculated from image to experimental data. Erhlich et al., 1991 created physical models for permeability based on the relation between pores and throat size.

This study intends to differentiate the parameters porosity and permeability in carbonate rocks through different methods of gauging/measuring and to understand the limiting factors of each methodologies in order to identify the effect of microporosity on permeability.

\section{Data Set}

The input data from this research were published on Oliveira et al., 2016 and Lima Neto et al., 2018.

The set of 13 samples from South Oman were classified as limestone, dolomitic limestone (dolomite $10 \%$ to $50 \%$ ) and dolomite according to Flügel (2010) based from geochemical characterization of the mineral phases through XRD (X-Ray Diffractrometry). According to petrographic thin-section analysis, all samples present intercrystalline porosity due to the recrystallization of the matrix calcitic mud- which also governs the texture of the samples - and is almost always associated with some other type of porosity, such as moldic, intraparticle or vugs. The textural classification by Dunham (1962) indicates packstone, wackstone, mudstone and crystalline (for dolomite). Analysis of the constituent minerals fraction helped in the textural classification. Table 1 indicates the constituent minerals fraction and Figure 1 shows some 
thin section of different lithological and textural classifications and porosity type.

Table 1 - Summary of the XRD results. Last column shows the lithological classification according to Flügel (2010) and based on the mineral constant estimates.

\begin{tabular}{|c|c|c|c|c|c|}
\hline \multirow{2}{*}{ Sample } & \multicolumn{4}{|c|}{ XRD Fraction (\%) } & \multirow{2}{*}{\begin{tabular}{|c|} 
Lithologic \\
Classification (Fügel, \\
2010) \\
\end{tabular}} \\
\hline & Calcite & Dolomite & Quartz & Halite & \\
\hline$A 1-1-3.3 K$ & 99.68 & 0.06 & 0.25 & 0.0 & Limestone \\
\hline $\mathrm{A} 1-1-17.0 \mathrm{H}$ & 98.72 & 0.58 & 0.22 & 0.47 & Limestone \\
\hline B-1-1-0.0E & 82 & 17.97 & 0.0 & 0.04 & Dolomitic Limestone \\
\hline B1-1-3.11E & 79.04 & 6.19 & 14.05 & 0.72 & Dolomitic Limestone \\
\hline B1-1-6.5F & 75.46 & 23.24 & 0.62 & 0.68 & Dolomitic Limestone \\
\hline B1-1-14.0I & 82.15 & 15.41 & 2.44 & 0.0 & Dolomitic Limestone \\
\hline B2-1-2.8| & 95.53 & 3.81 & 0.03 & 0.63 & Limestone \\
\hline B2-1-5.0E & 96.33 & 3.32 & 0.31 & 0.04 & Limestone \\
\hline B2-1-XA & 75.5 & 20.71 & 2.19 & 1.6 & Dolomitic Limestone \\
\hline BX-1-0.5D & 0.0 & 94.11 & 0 & 5.89 & Dolomite \\
\hline BX-1-D2F & 0.0 & 99.93 & 0.07 & 0.0 & Dolomite \\
\hline BX-1-D3H & 0.0 & 99.84 & 0.0 & 0.16 & Dolomite \\
\hline BX-1-D4.0.31 & 0.0 & 97.06 & 1.97 & 0.97 & Dolomite \\
\hline
\end{tabular}

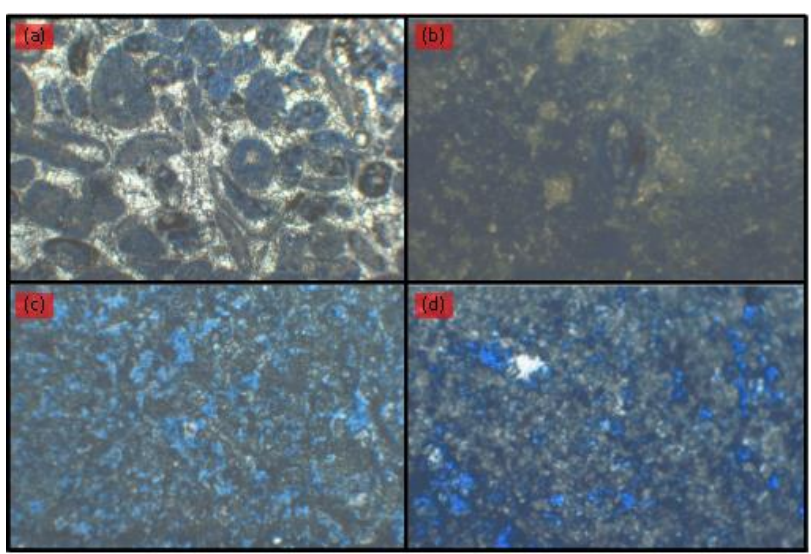

Figure 1: (a) The thin-section is showing an example of the limestone with packstone texture intraparticle porosity and intercrystalline microporosity. (b) The limestone with texture type wackstone (presence of calcite shells and bioclasts skeletal partially preserved). Shows intercrystalline microporosity due to mud fabric and intraparticle by dissolution of grains. (c) The $\mathrm{B} 1 / 1(0.0) \mathrm{E}$ thin section shows carbonate mud with recrystallized dolomite. The intercrystalline porosity produced by recrystallization of limestone to dolomite created vuggy pores generating an interconnected pore system. (d) This dolomite with crystalline dolostone texture details the intercrystalline porosity, dolomitization and dissolution processes causing the separate vuggy porosity.

\section{Method}

\section{Laboratory Technique}

A poropermeameter instrument (Coreval 700) was used to determine rock permeability through an unsteady state known as to the pressure-falloff method. This technique was developed by Jones (1972) and consists in a transient pulse-decay methodology. According to Jones (1972), the instantaneous flow rate can be estimated from the pressure falloff curve (API, 1998). In this work we use helium gas for flow rate estimates. Operational procedures were briefly described by Oliveira et al., 2016.

The confining pressure used was 600 psi and equipment requires pore volume, grain volume, and grain density as input parameters for porosity and permeability estimations. An Ultrapore-300 helium gas expansion porosimeter conducted in steady-state and based on gas expansion under Boyle's law was used to measure the input parameters (Oliveira et al., 2016 explains the operation schematic of equipment).

Experimental measurements of petrophysical properties through the expansion of gas enable coverage of the entire porous space. Thereby, the porosity and permeability measurements are influenced by the microporous portion, which in reservoir rocks conserves the immobile fluids, so as pores in micron scale do not affect the flow (Movers and Budd, 1996).

\section{Digital Image Analysis (DIA)}

The DIA method proposed (digital image analysis) allows a 2D description (thin section) of pore shape parameters and consists of three steps: image acquisition, image reconstruction and segmentation and estimation of pore shape parameters. Figure 2 shows a flowchart of the DIA procedures.

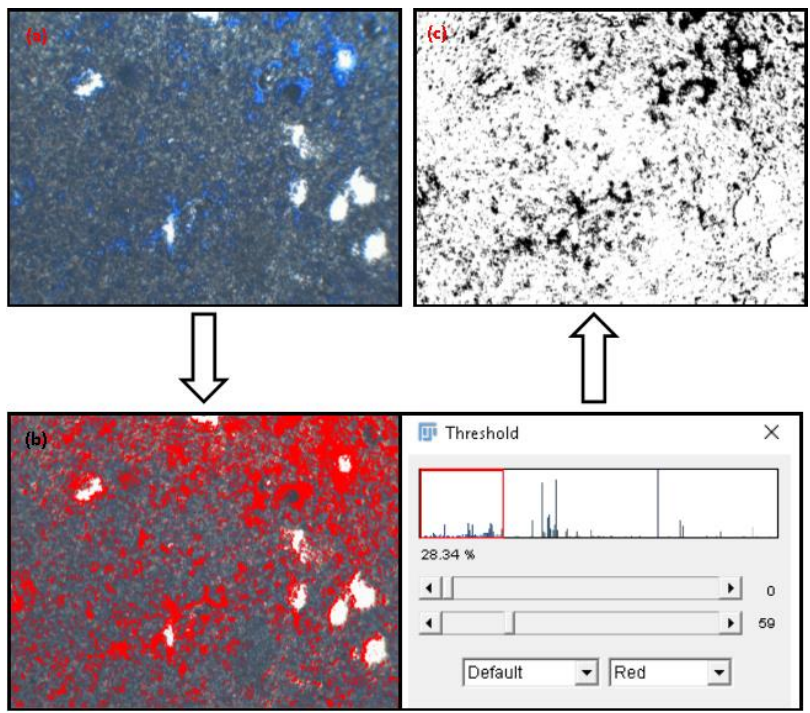

Figure 2 - Flowchart of the DIA procedures for obtaining porosity by image analysis. The original image in 24-bit and converted to 8-bit (a). The differentiation between pores and grains through the threshold method (b) and the binarization process for counting pixels (black and white) (c).

The digital color images were acquired and stored in 24bit files in RGB model. For segmentation using the ImageJ software, the images must be converted to 8-bit, that was performed using the IrfanView software. The porosity analysis was done in ImageJ, using The JPor 
algorithm (Grove and Jerram, 2011) as the thresholding method, which allows choosing the best differentiation between grains and pores. The binarization process aims to segment the image in pore and solid (mineral) phases. Porosity can be calculated through the ratio between the pore and the total area of the images.

A particle identification process is used for analyzing individual pore geometry through ellipse adjustment techniques, which provide the estimation of axis slope, aspect ratio and other geometrical parameters. In this way, it is possible to calculate pore shape parameters and petrophysical properties such as permeability through Kozeny-Carman theory (Equation 1) (Redefined by Mortensen et al., 1998).

kest $=c \emptyset^{3} / \mathrm{S}^{2}$

This Kozeny-Carman equation considers specific surface area (S), porosity (ø) and Kozeny factor (c) that could be obtained through Equation 2.

$c=\left(4 \cos \left(1 / 3 \arccos \left(\varnothing\left(64 / \pi^{3}\right)-1\right)+(4 / 3) \pi\right)+4\right)^{-1}$

\section{Results}

The laboratory data gives total porosity values, while DIA predicts values of macroporosity, in this way the microporosity was calculated through the difference between total porosity and macroporosity.

The microporosity of all the sample this study is formed basically by the matrix microporous (due to size of calcitic mud grains), recrystallized calcite and dolomite.

Most samples are formed by more than $50 \%$ microporosity in their porous system, and the permeability is driven by combination between macroporosity and microporosity. Except for those in which the porosity exceeds $80 \%$, in these samples the microporosity controls the permeability (Fullmer et al., 2014). Figure 3 shows the difference between microporosity and macroporosity on total porosity.

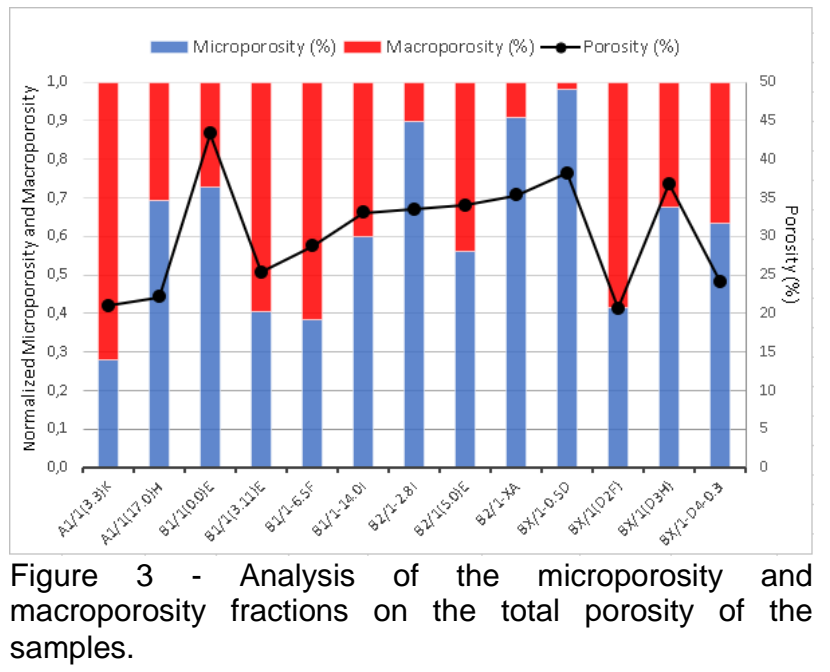

Relationship between some pore shape parameters from DIA helps in the analysis of pore network complexity of sample set. In Figure 4, the crossplot between PoA (perimeter over area) and Domsize (dominant pore size) recognize and separate the samples according to textural classification (Weger et al., 2009).

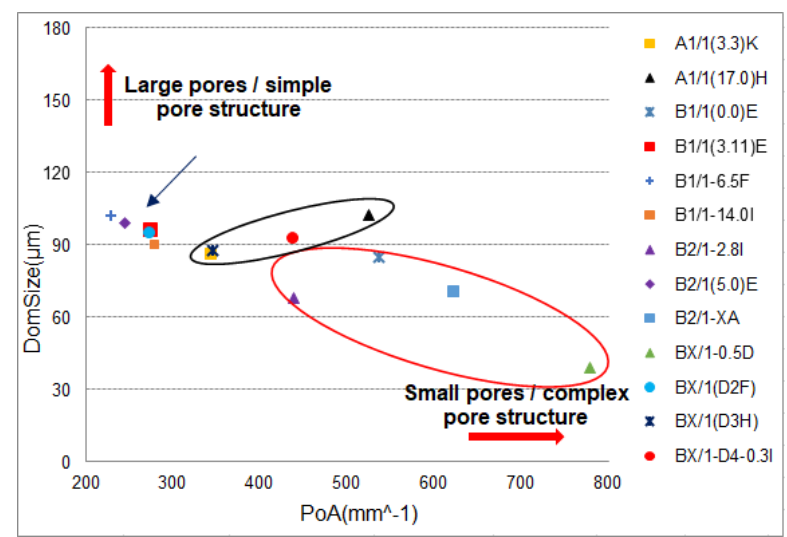

Figure 4 - Crossplot of PoA versus DomSize indicating the complexity of the samples.

Most of the samples indicated by the blue arrow are wackstone texture with intercrystalline, vugs and moldic pores. Except one sample that is a dolomite composed by crystalline texture with vugs. The black circle display packstone with recrystallized calcitic matrix and crystalline dolomite with some intraparticle porosity. Finally, the samples bounded by the red circle are crystalline dolomite, dolomitic limestone with crystalline and wackstone texture and limestone with wackstone texture, all the samples show basically intercrystalline porosity in micron scale.

Figure 5 shows the measured permeability influenced by total porosity and the relationship between permeability and porosity of macropores fraction.

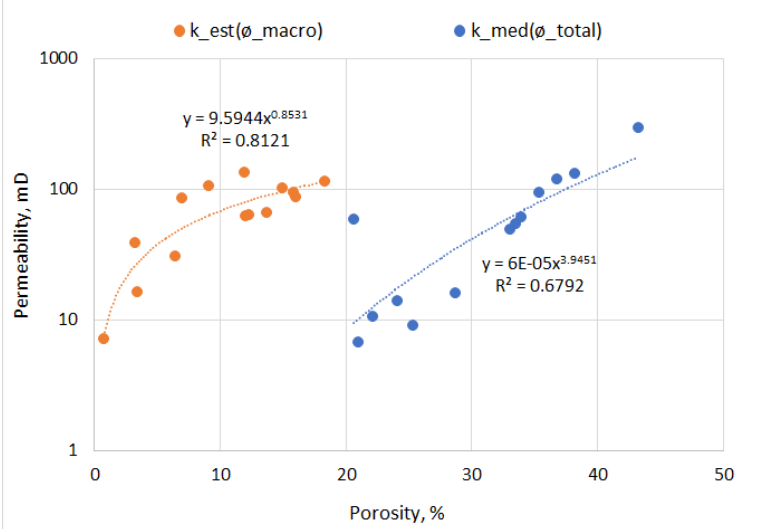

Figure 5 - Crossplot of macroporosity versus macro fraction permeability (kest) (orange dots) and total porosity versus total permeability ( $k_{\text {med }}$ ) (blue dots). Dashed lines represent best-fitting trendlines. 
Note that the poor relationship between total permeability and total porosity, while the relationship between permeability and porosity of the macropore fraction is higher. This behavior occurs because the total permeability of the samples is influenced by different porous systems some dominated by microporosity, while other exhibited a combination between microporosity and macroporosity.

To evaluate the influence of microporosity in the obtained parameters, the ratio between microporosity and total porosity was compared with the ratio between permeability estimated from DIA (macroporosity) and permeability total. The results show the microporosity values contribute to improve the permeability measured results (Figure 6). Each sample presents a percentage of micropores different from each other. This difference helps to correct the effect of microporosity on permeability measurements.

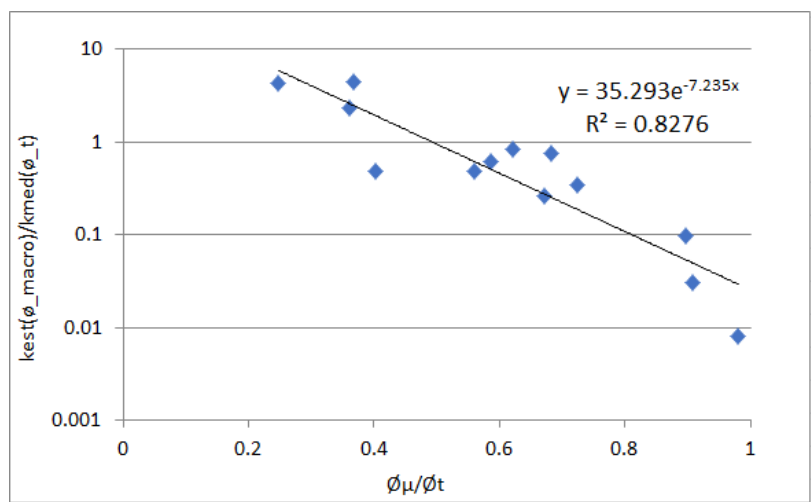

Figure 6 - Contribution of microporosity to permeability measurements.

Equation 3 summarizes the relation with the contribution of microporosity.

$\mathrm{kt}^{\prime}=\mathrm{kest} /\left(35.293 \mathrm{e}^{-7.235(\varnothing \mu / \varnothing \mathrm{t})}\right)$

\section{Conclusions}

The combination of DIA and laboratory technique offers the opportunity to dimension the contribution of microporosity in porosity and permeability despite the limiting factors of each method.

The macro and micropore fraction are sensitive to texture and pore type. The size of the grain affects the complexity of the pore network, so the smaller the dominant size of the grain, the more complex the structure.

Microporosity controls permeability, depending on the amount of micropores present in the porous system. Samples in which microposority is totally dominant, the values of both total porosity and total permeability of the sample tend to be overestimated, due to the particularities of the method. However, the contribution of microporosity helped in the difference in the deviation of the results when related to the results of the macroporous fraction $\left(R^{2}=0.828\right)$. Samples composed by the combination of macro and micropores, the fraction in micron scale tends to reduce the total permeability of the samples studied.

\section{Acknowledgments}

The authors acknowledge Statoil for financial support Contract No. 4600021098. GO thanks PRH-Petrobras226 for scholarship. Authors thank UENF / LENEP for all environment and structure provided to the execution of this work. This study was financed in part by the Coordenação de Aperfeiçoamento de Pessoal de Nível Superior - Brasil (CAPES). MC and RM thanks INCT/Geofisica and PRH-226-Petrobras for financial support; and also, CNPq for their Research Grants of Productivity in Technological Development and Innovation - DT II.

\section{References}

API, 1998. Recommend Practices for Core Analysis. RP40. American Petroleum Institute. 2nd ed.

BACHLE, G., WEGER, R., EBERLI, G., AND MASSAFERRO, J., 2004, The role of macroporosity and microporosity in constraining uncertainties and in relating velocity to permeability in carbonate rocks: SEG 74th Annual Meeting, Dallas, Texas.

BASHAH N. S. I. and PIERSON, B. 2012. The Impact of Pore Geometry and Microporosity on Velocity-Porosity Relationship in Carbonates of Central Luconia, Sarawak. AAPG International Conference and Exhibition, Singapore.

CANTRELL, D. L., AND HAGERTY, R. M., 1999. Microporosity in arab formation carbonates, Saudi Arabi. GeoArabia, V.4, N. 2.

CLERKE, E., 2007 Permeability, Relative Permeability, Microscopic Displacement Efficiency and Pore Geometry of M_1 Bimodal Pore Systems in Arab-D Limestone. In: SPE Middle East Oil and Gas Show and Conference, Bahrain. doi: 10.2118/105259-PA.

DUNHAM, R. J., 1962. Classification of carbonate rocks according to depositional texture, in W. E. Ham, ed., Classifications of carbonate rocks-a symposium: AAPG Memoir 1, p. 108-121.

EBERLI, G. P., BAECHLE, G. T., WEGER, R., MASSAFERRO J., 2004. Quantitative Discrimination of Effective Porosity Using Digital Image Analysis Implications for Porosity-Permeability Transforms. In: $66^{\text {th }}$ EAGE Conference, Paris.

EHRLICH, R., STERLING, J.C., HORKOWITZ, K.O. AND HORKOWITZ, J.P., 1991. Petrography and reservoir physics 1: Objective classification of reservoir porosity. AAPG, v.75, No.10, p.1547-1562.

FLÜGEL, E., 2010. Microfacies of carbonates rocks. Analysis, Interpretation and Application, p. 54. In E. Flügel, Microfacies of Carbonate Rocks, 2nd ed., p. 984.

FULLMER, S. M., Guidry, S., Gounay J., Bowlin, M., Ottinger, G., Al Neyadi, A., Gupta, G., Gao, G., Edwards, 
E., 2014. Microporosity: Characterization, Distribution and Influence on oil Recovery. International Petroleum Technology Conference, Doha, Qatar. doi: 10.2523/iptc17629-ms

GROVE, C. AND JERRAM, D.A., 2011. jPOR: An ImageJ Macro to Quantify Total Optical Porosity from Blue-Stained Thin Sections. Computers \& Geosciences, 37, 1850-1859. doi: 10.1016/j.cageo.2011.03.002

JONES, S. C., 1972. A rapid accurate unsteady-state Klinkenberg Permeameter. Society of Petroleum Engineers Journal. SPE3535-PA, 383-397. doi: 10.2118/3535-PA.

KNACKSTEDT M. A., SOK, R. M., SHEPPARD, A. P., LATHAM, S. J., MADADI, M., VARSLOT, T., ARNS, C. H., BACHLE G, EBERLI, G. P., 2008. Probing Pore Systems in Carbonates: Correlations to Petrophysical Properties. In: SPWLA 49th Annual Logging Symposium, Edinburgh, Scotland.

LIMA NETO, I., CEIA, M. A. R.,MISSÁGIA, R. M., OLIVEIRA, G. L. P., SANTOS, V. H., PARANHOS, R. P.R., ARCHILHA, N. L., 2018. Testing and evaluation of 2D/3D digital image analysis methods and inclusion theory for microporosity and S-wave prediction in carbonates. Marine And Petroleum Geology, v. 97, p. 592-611. doi: 10.1016/j.marpetgeo.2018.08.004

LUCIA, F. J., 1983. Petrophysical parameters estimated from visual description of carbonate rocks626-637.: a field classification of carbonate pore space: Journal of Petroleum Technology, March, v. 35, pp. 629-637.

LUCIA, F.J., 1995. Rock fabric/petrophysical classification of carbonate pore space for reservoir characterization. AAPG Bull 79, 9. pp. 1275-1300.

MORTENSEN, J., F. ENGDTROM, AND I. LIND, 1998. The relation among porosity, permeability, and specific surface of chalk from the Gorm field, Danish North Sea: SPE Reservoir Evaluation and Engineering, v. 1, no. 3, SPE31062-PA, p. 245-251, doi:10.2118/31062-PA.

MOVERS, T.T. AND BUDD, D.A., 1996. Quantification of porosity and permeability reduction due to calcite cementation using computer-assisted petrographic image analysis techniques. AAPG, v .80, N.3, p309-322.

OLIVEIRA, G. L. P., CEIA, M. A. R., MISSAGIA, R. M., ARCHILHA, N. L., FIGUEIREDO, L., ; SANTOS, V. H., LIMA NETO, I., 2016. Pore volume compressibilities of sandstones and carbonates from Helium porosimetry measurements. Journal of petroleum science and engineering, $\quad$ v. 137, p. 185-201. doi: 10.1016/j.petrol.2015.11.022

OLIVEIRA, G.; CEIA, M. ; MISSAGIA, R. ; SANTOS, VI. ; LIMA NETO, I., 2016. Permeability dependence of porosity and p-wave velocity in carbonate rocks. In: SEG Technical Program Expanded Abstracts 2016, 2016, Dallas. SEG Technical Program Expanded Abstracts 2016, 2016. p. 3272. doi: 10.1190/segam201613947676.1
SCHÖN, J.H., 2011. Physical Properties of Rocks: a workbook. Handbook of Petroleum Exploration and Production, Elsevier, vol. 8..

SHABANINEJAD, M., HAGHIGHI, M. B., 2011. Rock typing and Generalization of Permeability - Porosity Relationship for an Iranian Carbonate Gas Reservoir. In: Nigeria Annual International Conference and Exhibition Abuja, Nigeria. Society of Petroleum Engineers. doi: 10.2118/150819-MS. 